\title{
Make vs Buy in a Monopoly with Demand or Cost Uncertainty ${ }^{1}$
}

\author{
Luca Lambertini \\ Department of Economics, University of Bologna \\ Strada Maggiore 45, 40125 Bologna, Italy \\ luca.lambertini@unibo.it \\ ENCORE, University of Amsterdam
}

Roeterstraat 11, WB1018 Amsterdam, The Netherlands

May 21, 2009

\footnotetext{
${ }^{1}$ I would like to thank Emanuele Bacchiega, Giacomo Calzolari, Claudio Dalle Donne, Davide Dragone, Paolo Garella, Andrea Mantovani, Arsen Palestini and Georges Zaccour for comments and discussion. The usual disclaimer applies.
} 


\begin{abstract}
The issue of technical progress under uncertainty is nested into the debate on vertical integration vs outsourcing, to show that, in general, the former is preferable to the latter in terms of both expected profits and technological efficiency. It is then shown that there exist (i) an optimal two part tariff where the unit price set by the upstream firm is conditional upon its R\&D effort, and (ii) an optimal contract specifying the input price in terms of the initial capabilities of the sub-contractor, whereby the industry replicates the same performance as the vertically integrated firm as for both profits and R\&D efforts.
\end{abstract}

Keywords: vertical integration, outsourcing, process innovation, uncertainty

JEL Codes: L12, L13, O31 


\section{Introduction}

A wide debate is currently taking place concerning the convenience for firms of making or buying intermediate goods to be used as inputs in the production process. This issue is closely related to choice between vertical integration and dis-integration, or, equivalently, with the opportunity of outsourcing. ${ }^{1}$

From a historical perspective, the evolution of capitalism is characterised by different phases, in each of which the tendencies to vertical integration or vertical dis-integration are more or less intense. Even if we confine our attention to the last decades, the economic development of industrialised countries over the period of the so-called economic boom (the Fifties and Sixties) seemed to be characterised by high incentives towards vertical integration. On the opposite, the Eighties witnessed a strong tendency to dis-integration, often interpreted as a way to increase flexibility (see Tadelis, 2002, inter alia). What is happening today, in the years of (the third wave of) "globalisation" is not clear, and this is reflected by a large literature discussing the various aspects of this issue over the last twenty years.

According to Grossman and Hart (1986), the failure of the internal incentive system, due to an incomplete assignment of property rights within the integrated firm, may provide an advantage for arm's length relationships. Additionally, the existence of a sufficiently competitive upstream market where firms may access intermediate inputs and raw materials at relatively low prices may lure more and more firms to choose outsourcing, with a remarkable bandwagon effect driving this process. If this effect is strong enough, then firm idiosyncratic levels of vertical integration within a given industry are unlikely to obtain at the equilibrium (see McLaren, 2000; Grossman and Helpman, 2002, 2005; Antras and Helpman, 2004).

On the other hand, it is by now part of the acquired wisdom that vertical integration can be considered as a remedy to the well known hold-up problem, with particular reference to situations where vertically related firms must

\footnotetext{
${ }^{1}$ For an overview of the early literature on vertical integration, see Perry (1989).
} 
rely on incomplete contracts to trade intermediate inputs whose quality (or performance) is unobservable and requires costly investments (Williamson, 1971; Grossman and Hart, 1986).

Several other factors may of course intervene to make the picture even more complicate, such as technological shocks, market integration, the coexistence of firms with different goals, and so on. However, to sum up in a nutshell the economists' dominant view on the choice between making or buying and its interplay with the global nature of the present-day economic system, one could say that globalisation favours a process of leaning or downsizing of firms, since subcontracting a large number of non-core activities of any given firm is of the essence to keep up with rivals. And yet, sound as it may seem at first glance, this view overlooks a few stylised facts that play a crucial role. A striking one is certainly that also core activities are outsourced: essential technologies are being bought on the international market, in several sectors. E.g., European or US firms operating in the hi-fi industry buy output stages for their products in China, with the consequence that the final product embodies very little proprietary technology of the firm that is selling it under her brand name. This may well appear unfair to the customer who believes to buy Italian, whatever meaning one may attach to such a slogan, but may ultimately have much more unpleasant consequences for the firm herself in the long run, as she will realise, sooner or later, that she's no longer able to build the product, as the essential know-how has been long lost. The same considerations seemingly apply to the European aeronautical industry, as emphasized by Pritchard and MacPherson (2007). This translates into the following question: is it wise to trade off short- or medium-run profit gains (provided such gains do exist) generated by outsourcing against the long-run damage associated to the perspective of loosing essential capabilities in terms of R\&D and, more generally, know-how?

The present paper tackles some aspects of this issue using a stripped-down model where, alternatively, a vertically integrated monopolist carries out all 
of its activities (R\&D and the production of the final good $)^{2}$ internally, or two vertically related but independent firms carry out one activity each, with the upstream firm taking care of $\mathrm{R} \& \mathrm{D}$ and selling the input (a component or an intermediate good) to the downstream firm assembling and selling the final good. Uncertainty enters the model in the form of either a shock on demand or a shock on the R\&D technology. In the first situation, the resulting technology is more efficient and expected industry profits are larger under vertical integration than under outsourcing. Hence, the model speaks in favour of internalising all the activities inside a single firm. In the second scenario, R\&D incentives are still higher under vertical integration, while the comparative assessment of expected industry profits favours vertical integration only for sufficiently low levels of the variance of the technological shock.

Additionally, I examine the viability of three different contractual agreements designed to drive the expected industry profits and the related R\&D efforts under outsourcing to the same levels they would attain under vertical integration. The first is a classic two-part tariff whereby the input is traded at marginal cost, plus a fixed fee: it turns out that such a contract cannot be adopted as it jeopardise the upstream firm's R\&D incentives altogether. The second scheme modifies the first in such a way that the two part tariff indeed allows firms to replicate the performance of the vertically integrated one, by establishing that the franchising contract must take explicitly into account the timing of the decisions being taken by the upstream firm in terms of R\&D effort and input price. To illustrate that the same outcome can be achieved along an alternative route, the third scheme consists in specifying contractually the input price ex ante in terms of the initial technological capabilities of the upstream firm. This is accompanied by a compensation from

\footnotetext{
${ }^{2}$ The $R \& D$ considered here is for process innovation, i.e., the investment is aimed at reducing the production costs of the final good, taking any other specs of the latter as given. This is admittedly a restrictive assumption. However, it can be argued that, all else equal, a reduction of the unit cost can be perceived by the final consumer as grossly equivalent to an increase in product quality (see Futia, 1980).
} 
the downstream firm to the upstream one, playing the role of a risk-sharing agreement. I show that this solution is viable and indeed allows the two vertically related firms to exactly replicate the expected profit performance that a vertically integrated firm would attain.

\section{The setup}

Consider a single-product monopolist facing a downward sloping market demand and choosing (i) the amount of final good to be supplied to the market, and (ii) whether to carry our R\&D efforts in house or to resort instead to outsourcing. The environment is affected by either demand uncertainty or technological uncertainty. Accordingly, one may examine four possible cases:

I. All activities are carried out in house and uncertainty affects market demand. If so, the latter takes the form $p=a-q / \theta$, where $p$ is the market price of the final good, $a$ is the reservation price, $q$ is the amount of production (or equivalently, sales) and $\theta$ is a shock on the slope of the demand function, with $E(\theta)=1$ and $E\left(\theta^{2}\right)=\sigma^{2}$. Accordingly, one has $E(1 / \theta)=s>1$ by Jensen's inequality. ${ }^{3}$ Producing the final output entails a cost $C(q)=z q,{ }^{4}$ where marginal cost $z$ decreases according to an R\&D technology represented by $z=z_{0}-k, k$ being the R\&D effort, whose cost is $\Gamma(k)=b k^{2}, b>0$. Hence, the objective of the firm is to maximise the following expected profits:

$$
E \pi_{H}=E[(p-z) q]-b k^{2}
$$

w.r.t. quantity $q$ and the intensity of the $\mathrm{R} \& \mathrm{D}$ investment $k$. Subscript $H$ stands for in house.

\footnotetext{
${ }^{3}$ Alternatively, one could consider an additive shock whereby $p=a-q-\varepsilon$, with $E(\varepsilon)=$ 0 and $E\left(\varepsilon^{2}\right)=\omega^{2}$. However, in such a case the optimal output would be deterministic and uncertainty wouldn't affect the optimal behaviour of the firm (for additional aspects of this issue, see Klemperer and Meyer, 1986). See also Sandmo (1971) and Leland (1972).

${ }^{4}$ Throughout the paper, fixed costs are assumed away as they are immaterial to the ensuing analysis.
} 
II. The type of uncertainty is the same as in the previous case but the firm resorts to outsourcing. That is, she receives the component (or a generic intermediate good) from an independent upstream firm that also carries out the R\&D effort. Assume for simplicity that the production of one unit of the final good requires one unit of the outsourced intermediate good or component, which is traded at a unit price $c$ chosen by the OEM firm. Define the latter as the upstream $(U)$ firm, and the unit selling the final good as the downstream $(D)$ firm. This has to choose quantity $q$ to maximise expected profits

$$
E \pi_{D}=E[(p-c) q]
$$

while the upstream firm chooses $c$ and $k$ to maximise

$$
E \pi_{U}=E[(c-z) q]-b k^{2} .
$$

This is a Stackelberg (i.e., sequential play) game with firm $u$ moving first and firm $D$ moving second, to be solved by backward induction so as to characterise the subgame perfect equilibrium.

III. In the alternative case, uncertainty affects the outcome of the R\&D investment. The integrated firm carrying out innovation in house has a technology $z=z_{0}-k+\varepsilon$, with $E(\varepsilon)=0$ and $E\left(\varepsilon^{2}\right)=\omega^{2}$, while the demand function is deterministic: $p=a-q$. Therefore, the monopolist has to set $q$ and $k$ to maximise $E \pi_{H}=E\left[(p-z) q-b k^{2}\right]$.

IV. The last setup is the variant of III, with the downstream monopolist opting for outsourcing, with $E \pi_{D}=E[(p-c) q]$. The upstream OEM firm sets $k$ to maximise $E \pi_{U}=E\left[(c-z) q-b k^{2}\right]$.

\section{In house R\&D with demand shocks}

The monopolist's expected profit function writes as follows:

$$
E \pi_{H}=E\left[\left(a-\frac{q}{\theta}-z_{0}+k\right) q\right]-b k^{2} .
$$


The associated first order conditions (FOCs) are

$$
\begin{aligned}
& \frac{\partial E \pi_{H}}{\partial q}=a+k-2 s q-z_{0}=0 \\
& \frac{\partial E \pi_{H}}{\partial k}=q-2 b k=0
\end{aligned}
$$

since $E(1 / \theta)=s$, whereby

$$
E q^{*}=\frac{a+k-z_{0}}{2 s}
$$

and

$$
E k^{*}=\frac{a-z_{0}}{4 b s-1}>0
$$

for $b s>1 / 4 .^{5}$ The expected equilibrium profits are

$$
E \pi_{H}^{*}=\frac{b\left(a-z_{0}\right)^{2}}{4 b s-1}
$$

while the efficiency level of the firm is measured by the equilibrium marginal cost $E z_{H}^{*}=\left(a-4 b s z_{0}\right) /(1-4 b s)$. Note that, in view of the constraint $b s>1 / 4, E z_{H}^{*}>0$ iff $a>1 / 4$ and $b s \in(1 / 4, a)$.

The associated expected levels of consumer surplus and social welfare are:

$$
\begin{gathered}
E C S_{H}^{*}=\frac{2 b^{2}\left(a-z_{0}\right)^{2}}{(4 b s-1)^{2}} \\
E S W_{H}^{*} \equiv E C S_{H}^{*}+E \pi_{H}^{*}=\frac{b[2 b(1+2 s)-1]\left(a-z_{0}\right)^{2}}{(4 b s-1)^{2}}
\end{gathered}
$$

which are clearly positive over the admissible parameter range specified above.

\footnotetext{
${ }^{5}$ This condition, ensuring the existence of an interior solution, also ensures stability and concavity. The detailed analysis of these aspects of the model are omitted for brevity. Note, however, that I will intentionally put aside the boundary solution $E k^{*}=0$ arising for all $b s \leq 1 / 4$ as this entails that the industry generates no technical progress at all.
} 


\section{Outsourcing with demand shocks}

Now suppose the firm selling the final good decides to buy the component from an upstream supplier who also takes care of investing in process innovation. Solving the game by backward induction, the expected value of the output of firm $D$ is the outcome of the following problem:

$$
\max _{q} E \pi_{D}=E\left[\left(a-\frac{q}{\theta}-c\right) q\right]
$$

yielding

$$
\frac{\partial E \pi_{D}}{\partial q}=a-c-2 s q=0 \Leftrightarrow E q^{*}=\frac{a-c}{2 s}
$$

which must be plugged into the problem of firm $U$ :

$$
\max _{c, k} E \pi_{U}=E\left[(c-z) q^{*}\right]-b k^{2}=\frac{(a-c)\left(c+k-z_{0}\right)}{2 s}-b k^{2} .
$$

This produces the FOCs:

$$
\begin{aligned}
& \frac{\partial E \pi_{U}}{\partial c}=\frac{a-2 c-k+z_{0}}{2 s}=0 \\
& \frac{\partial E \pi_{U}}{\partial k}=\frac{a-c-4 b s k}{2 s}=0
\end{aligned}
$$

whose solution is the pair of optimal strategies:

$$
\begin{aligned}
E c_{U}^{*} & =\frac{a-k^{*}+z_{0}}{2} \\
E k_{U}^{*} & =\frac{a-z_{0}}{8 b s-1}
\end{aligned}
$$

so that equilibrium output, marginal cost and profits are

$$
\begin{aligned}
E q_{D}^{*} & =\frac{2 b\left(a-z_{0}\right)}{8 b s-1} ; E z_{U}^{*}=\frac{a-8 b s z_{0}}{1-8 b s} \\
E \pi_{U}^{*} & =\frac{b\left(a-z_{0}\right)^{2}}{8 b s-1} ; E \pi_{D}^{*}=\frac{4 b^{2}\left(a-z_{0}\right)^{2} s}{(8 b s-1)^{2}}
\end{aligned}
$$

Provided $a>1 / 8$, The interior solution is viable for all $b s \in(1 / 8, a)$. 
The corresponding expected consumer surplus and social welfare are:

$$
\begin{gathered}
E C S_{U D}^{*}=\frac{2 b^{2}\left(a-z_{0}\right)^{2}}{(8 b s-1)^{2}} \\
E S W_{U D}^{*} \equiv E C S_{U D}^{*}+E \pi_{U}^{*}+E \pi_{D}^{*}=\frac{b[2 b(1+6 s)-1]\left(a-z_{0}\right)^{2}}{(8 b s-1)^{2}} .
\end{gathered}
$$

\section{Make or buy with demand shocks}

Given the constraint ensuring the existence of an interior solution, the two cases outlined above are both admissible for $b s \in(1 / 4, a)$ provided $a>1 / 4$. A quick inspection of the foregoing analysis allows to state:

Proposition 1 Suppose $a>1 / 4$ and $b s \in(1 / 4, a)$. If so, then (i) $E z_{U}^{*}>$ $E z_{H}^{*}$; (ii) $E \pi_{H}^{*}>E \pi_{U}^{*}+E \pi_{D}^{*}$; and (iii) $E C S_{H}^{*}>E C S_{U D}^{*}$ over the entire admissible parameter range.

That is, in the region of parameters where both interior solutions exist, investing in house is preferable to outsourcing in terms of both the resulting level of technological efficiency and industry profits. A fortiori, the firm supplying the final good should prefer carrying out R\&D internally as $E \pi_{H}^{*}>E \pi_{D}^{*}$. The explanation is to be found in the double marginalisation characterising the outsourcing solution, which (i) distorts the distribution of surplus along the vertical channel, all else equal, and (ii) as a result, lowers firm $U$ 's incentive to innovate as compared to what the integrated firm would find it optimal: indeed $E k_{H}^{*}>E k_{U}^{*}$. Note that, as a result of the absence of double marginalisation, the quantity becomes larger, $E q_{H}^{*}>E q_{D}^{*}$. Overall, vertical integration entails a lower marginal cost because of higher R\&D investments and consequently a larger output at a lower market price. The balance of these effects produces a profit increase. In view of the current debate on outsourcing in a global economy, this setup illustrates a situation where vertical integration dominates outsourcing in all respects. To complete the picture, $E q_{H}^{*}>E q_{D}^{*}$ implies $E C S_{H}^{*}>E C S_{U D}^{*}$ (and therefore also $\left.E S W_{H}^{*}>E S W_{U D}^{*}\right)$. 


\section{In house R\&D with technological shocks}

Examine the setup where the shock affects the $R \& D$ activity. The integrated firm wants to maximise

$$
E \pi_{H}=E\left[(a-q-z) q-b k^{2}\right]
$$

w.r.t. $q$ and $k$, s.t. the technological constraint $z=z_{0}-k+\varepsilon$. The FOCs are:

$$
\begin{aligned}
& \frac{\partial E \pi_{H}}{\partial q}=a+k-2 q-z_{0}=0 \\
& \frac{\partial E \pi_{H}}{\partial k}=q-2 b k=0
\end{aligned}
$$

yielding

$$
E q_{H}^{*}=\frac{2 b\left(a-z_{0}\right)}{4 b-1} ; E k_{H}^{*}=\frac{a-z_{0}}{4 b-1} ; E z_{H}^{*}=\frac{a-4 b z_{0}}{1-4 b}
$$

and

$$
E \pi_{H}^{*}=\frac{b\left(a-z_{0}\right)^{2}}{4 b-1} .
$$

Expected consumer surplus and welfare are

$$
\begin{gathered}
E C S_{H}^{*}=\frac{2 b^{2}\left(a-z_{0}\right)^{2}}{(4 b-1)^{2}} \\
E S W_{H}^{*} \equiv E C S_{H}^{*}+E \pi_{H}^{*}=\frac{b(6 b-1)\left(a-z_{0}\right)^{2}}{(4 b-1)^{2}} .
\end{gathered}
$$

This solution is acceptable if $b>1 / 4$ and $z_{0}>a /(4 b)$.

\section{Outsourcing with technological shocks}

Here an independent upstream firm works out the intermediate good and the related R\&D activity, while the downstream firm chooses the output level only. By backward induction, we start by considering the problem of firm $D$ :

$$
\max _{q} E \pi_{D}=E[(a-q-c) q] \Leftrightarrow E q_{D}^{*}=\frac{a-c}{2} .
$$


The expression $E q_{D}^{*}$ can be plugged into firm $U$ 's expected profit function:

$$
E \pi_{U}=E\left[(c-z) E q_{D}^{*}\right]-b k^{2}=\frac{(a-c)\left(c+k-z_{0}\right)}{2}-b k^{2},
$$

the FOCs w.r.t. $c$ and $k$ being:

$$
\begin{aligned}
& \frac{\partial E \pi_{U}}{\partial c}=\frac{a-2 c-k+z_{0}}{2}=0 \\
& \frac{\partial E \pi_{U}}{\partial k}=\frac{a-c-4 b k}{2}=0
\end{aligned}
$$

whose solution is

$$
\begin{aligned}
E c_{U}^{*} & =\frac{a-k^{*}+z_{0}}{2} \\
E k_{U}^{*} & =\frac{a-z_{0}}{8 b-1}
\end{aligned}
$$

The resulting expected equilibrium profits are

$E \pi_{U}^{*}=\frac{8 b\left[\left(a-z_{0}\right)^{2}+\omega^{2}\right]-\omega^{2}}{8(8 b-1)} ; E \pi_{D}^{*}=\frac{16 b\left[4 b\left(\left(a-z_{0}\right)^{2}+\omega^{2}\right)-\omega^{2}\right]+\omega^{2}}{16(8 b-1)^{2}}$

both strictly positive for any level of the variance $\omega^{2}$, with

$$
E q_{D}^{*}=\frac{2 b\left(a-z_{0}\right)}{8 b-1} ; E z_{U}^{*}=\frac{a-8 b z_{0}}{1-8 b} .
$$

As for expected consumer surplus and social welfare, we have:

$$
\begin{gathered}
E C S_{U D}^{*}=\frac{16 b\left[4 b\left(\left(a-z_{0}\right)^{2}+\omega^{2}\right)-\omega^{2}\right]+\omega^{2}}{32(8 b-1)^{2}} \\
E S W_{U D}^{*} \equiv E C S_{U D}^{*}+E \pi_{U}^{*}+E \pi_{D}^{*}=\frac{32 b(14 b-1)\left(a-z_{0}\right)^{2}+7(8 b-1)^{2} \omega^{2}}{32(8 b-1)^{2}} .
\end{gathered}
$$

This equilibrium is admissible over the entire parameter region wherein the vertically integrated problem admits an internal solution. 


\section{Make or buy with technological shocks}

Comparing $E z_{U}^{*}$ and $E z_{H}^{*}$ for $b>1 / 4$, one immediately verifies:

Proposition 2 In the parameter range where interior solutions exist, $E z_{U}^{*}>$ $E z_{H}^{*}$.

The comparative assessment of expected industry profits depends instead on the variance of the shock:

Lemma $3 E \pi_{H}^{*}>E \pi_{U}^{*}+E \pi_{D}^{*}$ for all

$$
\omega^{2} \in\left(0, \frac{256 b^{3}\left(a-z_{0}\right)^{2}}{3(8 b-1)^{2}(4 b-1)}\right)
$$

and conversely for any $\omega^{2}$ outside such a range.

Similarly, as for expected consumer surplus and social welfare, we have:

Lemma $4 E C S_{H}^{*}>E C S_{U D}^{*}$ for all

$$
\omega^{2} \in\left(0, \frac{512 b^{3}(6 b-1)\left(a-z_{0}\right)^{2}}{3(8 b-1)^{2}(4 b-1)^{2}}\right)
$$

while $E S W_{H}^{*}>E S W_{U D}^{*}$ for all

$$
\omega^{2} \in\left(0, \frac{1024 b^{3}(5 b-1)\left(a-z_{0}\right)^{2}}{3(8 b-1)^{2}(4 b-1)^{2}}\right)
$$

and conversely.

Given that

$$
\frac{512 b^{3}(6 b-1)\left(a-z_{0}\right)^{2}}{3(8 b-1)^{2}(4 b-1)^{2}}>\frac{1024 b^{3}(5 b-1)\left(a-z_{0}\right)^{2}}{3(8 b-1)^{2}(4 b-1)^{2}}>\frac{256 b^{3}\left(a-z_{0}\right)^{2}}{3(8 b-1)^{2}(4 b-1)}
$$

in the region where $b>1 / 4$, Lemmata $3-4$ yield 
Proposition 5 For all

$$
\omega^{2} \in\left(0, \frac{512 b^{3}(6 b-1)\left(a-z_{0}\right)^{2}}{3(8 b-1)^{2}(4 b-1)^{2}}\right)
$$

private (profits) and social incentives are aligned in favouring vertical integration. In the intermediate range

$$
\omega^{2} \in\left(\frac{512 b^{3}(6 b-1)\left(a-z_{0}\right)^{2}}{3(8 b-1)^{2}(4 b-1)^{2}}, \frac{1024 b^{3}(5 b-1)\left(a-z_{0}\right)^{2}}{3(8 b-1)^{2}(4 b-1)^{2}}\right)
$$

vertical integration is socially efficient but outsourcing is more profitable. Finally, for all

$$
\omega^{2} \in\left(\frac{1024 b^{3}(5 b-1)\left(a-z_{0}\right)^{2}}{3(8 b-1)^{2}(4 b-1)^{2}}, \frac{512 b^{3}(6 b-1)\left(a-z_{0}\right)^{2}}{3(8 b-1)^{2}(4 b-1)^{2}}\right)
$$

outsourcing is both socially and privately convenient.

Note that in the second of the ranges considered in Proposition 5, vertical integration is socially preferable due to its beneficial effects on consumer surplus, that more than compensate the profit loss. Conversely, in the third, the profit loss suffered from the firm outweighs the gain still characterising consumer surplus, and therefore a social planner would be led to prefer outsourcing to vertical integration notwithstanding the effects on consumer surplus. Of course if the variance of the shock ends up being above the highest threshold, then also consumers prefer outsourcing.

\section{Two-part tariff vs contractible input price}

The remaining open question is whether the outsourcing solution can be corrected via a two-part tariff according to which firm $D$ buys $q$ units of the intermediate good or input from firm $U$ by paying a total amount equal to $T=c q+f$, where $c$ and $f$ are to be contracted upon in such a way that (i) 
the expected profit performance of the entire vertical channel (or industry) exactly replicates those of the vertically integrated monopolist, and (ii) the R\&D effort (and therefore also the quality of the intermediate good) is the same as in the vertically integrated case.

Irrespective of the type of shock being considered, we may examine the standard perspective where $c=z$ and $f=E \pi_{H}^{*}-\beta$, with $\beta \in\left[0, E \pi_{H}^{*}\right)$, exogenous to the model. That is, firm $D$ pays the input at marginal cost, plus an additional fixed fee which is at most equal to the expected profit generated by the in house solution (see, e.g., Tirole, 1988, ch. 4; Katz, 1989; and Martin, 2001).

Consider first the case of a demand shock. The downstream firm chooses the output level to maximise

$$
E \pi_{D}=E\left[\left(a-\frac{q}{\theta}-z\right) q\right]-E \pi_{H}^{*}+\beta
$$

yielding $E q^{*}=(a-z) /(2 s)$. Going backward to firm $U$ 's problem, imposing $c=z$ obviously implies that the expected gross profits from selling the input to firm $D$ drop to zero, the resulting expression being:

$$
E \pi_{U}=f-b k^{2}=E \pi_{H}^{*}-\beta-b k^{2} .
$$

Clearly, the above profits are everywhere decreasing in $k$, which suffices to prove that the proposed two-part tariff cannot reproduce the profit performance and the R\&D incentives of the vertically integrated firm. The same of course applies to the alternative case where the shock appears in the R\&D technology, as the essence of the problem is not the placement of the shock but the impossibility of aligning the upstream firm's incentives towards innovation. Indeed, it is very easy to verify that the argument goes through unmodified in the fully deterministic setup. Hence:

Proposition 6 The two-part tariff $T=c q+f$ cannot replicate the vertically integrated solution if the latter admits positive R\&D investments.

Obviously, the two-part tariff would work in case the corner solution prevailed under vertical integration, as the optimal amount of $R \& D$ would be 
zero in either case. However, this is a situation where there is no incentive whatsoever to generate technical progress and therefore, per se, a less interesting one. ${ }^{6}$

To get around this problem, one may consider the following perspective: instead of setting $c=z$ from the outset, just take $z=z_{0}-k$ for any $c$. This entails that the upstream objective function becomes:

$$
E \pi_{U}=E\left[\left(c-z_{0}-k\right) q^{*}\right]+E \pi_{H}^{*}-\beta-b k^{2}
$$

yielding the FOC:

$$
\frac{\partial E \pi_{U}}{\partial k}=\frac{a-c-4 b k}{2}=0
$$

whose solution w.r.t. $k$ coincides with the optimal in house R\&D effort $E k_{H}^{*}$, once $c$ has been set equal to $z=z_{0}-k$ in (2). Accordingly, also the profit performance of the channel exactly replicates that of the vertically integrated firm. This is summarised by:

Proposition 7 The optimal franchising contract indeed entails marginal cost pricing by the upstream firm, provided that the unit price be equal to the effective marginal cost characterising firm $U$ once the latter has carried out its RED $D$ effort.

What the above Proposition tells is that whether the pricing rule $c=z$ is set before or after writing the necessary condition (2) does make a crucial difference. So much for the mathematical structure of the model; its intuitive counterpart is that the contract must specify that "the unit price will be set at marginal cost conditional upon the completion of the R\&D activity by the upstream firm". What is of the essence here is the timing associated with the two decisions that the upstream firm has to take (and which the contract must spell out explicitly) in order to replicate the performance attainable

\footnotetext{
${ }^{6}$ The feasibility of two-part tariffs has been investigated in a similar environment in the marketing literature, where the issue is investing in advertising rather than in R\&D. See Jeuland and Shugan (1983) for a static approach, and Zaccour (2008) for a dynamic approach to this problem.
} 
under vertical integration. Realistically, a sound interpretation of events is that firm $U$ first carries out the R\&D project and then sets the price at the resulting marginal cost. If the franchising contract properly accounts for this proviso, then joint profits will indeed be maximised.

An alternative (and not equivalent) approach consists in making the input price $c$ contractible and set it ex ante so as to reproduce the performance of the vertically integrated monopolist whenever it is desirable to do so. ${ }^{7}$ To see how this works, take again the first model, with demand uncertainty. The problem of the upstream firm is now to maximise

$$
\max _{k} E \pi_{U}=\frac{(a-c)\left(c+k-z_{0}\right)}{2 s}-b k^{2}
$$

with $c$ being negotiated upon so as to attain the same overall expected profits for the vertical channel as the integrated monopolist. The optimal investment is

$$
E k_{U}^{*}(c)=\frac{a-c}{4 b s}
$$

so that the sum of the two firms' expected profits is

$$
E \pi_{U}^{*}(c)+E \pi_{D}^{*}(c)=\frac{(a-c)\left[a+c(8 b s-1)-8 b s z_{0}\right]}{16 b s^{2}}+\frac{(a-c)^{2}}{4 s} .
$$

Then, imposing

$$
E \pi_{U}^{*}(c)+E \pi_{D}^{*}(c)=E \pi_{H}^{*}=\frac{b\left(a-z_{0}\right)^{2}}{4 b s-1}
$$

yields the optimal (negotiated) input price

$$
\bar{c}_{U}=\frac{a-4 b s z_{0}}{1-4 b s}
$$

which ensures not only the replication of the profit performance of the vertically integrated firm, but also the exact replication of the R\&D effort associated to it, since it turns out that $E k_{U}^{*}\left(\bar{c}_{U}\right)=\left(a-z_{0}\right) /(4 b s-1)$.

\footnotetext{
${ }^{7}$ Recall that under technological uncertainty the vertically integrated solution is desirable only for sufficiently low levels of the shock variance.
} 
There remains to observe the resulting distribution of profits along the vertical channel is not the same as in the previous solution, although the overall channel profits are of course the same. The upstream firm's expected profits are:

$$
E \pi_{U}^{*}\left(\bar{c}_{U}\right)=-\frac{b\left(a-z_{0}\right)^{2}}{(4 b s-1)^{2}}<0
$$

that is, the upstream firm is loosing money in correspondence of the solution $\left(\bar{c}_{U}, k_{U}^{*}\left(\bar{c}_{U}\right)\right)$, precisely because she's undertaking a risky R\&D project ${ }^{8}$ with the stipulated objective of fully replicating the same optimal innovation as if she were the upstream division of a vertically integrated unit. Also, note that $\bar{c}_{U}=z_{H}^{*}$, i.e., the input is indeed traded at marginal cost. This seemingly coincides with what would happen in case the two-part tariff were adopted, with a crucial difference: while the two-part tariff would establish $c=z$ a priori (for a generic level of $c$ ) and therefore would jeopardize firm $U$ 's innovation incentives, the contract envisaged here stipulates that $c=\bar{c}_{U}$ which in turn is a function of the initial level of technological capabilities of firm $U$ as measured by $z_{0}$, not $z$. It goes without saying that the contract between $U$ and $D$ must also account for a compensation scheme (in the form of a side payment from $D$ to $U$ ) compensating the upstream firm and ultimately ensuring that her expected profits be non-negative.

The alternative case where the shock enters the R\&D technology lends itself to a largely analogous treatment. Firm $U$ has to

$$
\max _{k} E \pi_{U}=\frac{(a-c)\left(c+k-z_{0}\right)}{2}-b k^{2}
$$

for a given level of $c$. This yields the certainty-equivalent $R \& D$ effort $E k_{U}^{*}(c)=$ $(a-c) /(4 b)$. Next, one has to solve $E \pi_{U}^{*}(c)+E \pi_{D}^{*}(c)=E \pi_{H}^{*}$ to obtain the optimal (negotiated) input price

$$
\bar{c}_{U}=\frac{a-4 b z_{0}}{1-4 b} .
$$

\footnotetext{
${ }^{8}$ Although the shock affects in principle the demand function, it is nonetheless true that it exerts a tangible effect on the R\&D incentive, as demonstrated by the expression of $k_{U}^{*}\left(\bar{c}_{U}\right)$, which depends on $s$.
} 
Once again, the expected profit of firm $U$,

$$
E \pi_{U}^{*}\left(\bar{c}_{U}\right)=-\frac{b\left(a-z_{0}\right)^{2}}{(4 b-1)^{2}}
$$

is negative and therefore the contract must contemplate a compensation scheme making up for the profit loss. In both cases, irrespective of the nature of the shock, such a compensation scheme largely behaves as a risk-sharing arrangement.

\section{Concluding remarks and extensions}

The foregoing analysis has singled out the possibility that outsourcing undermines the long-run technological capabilities of a firm, as well as its profits, with the exception of the case where the $R \& D$ technology is affected by a shock whose variance be sufficiently large.

As an alternative to vertical integration, the industry may replicate the same profits by resorting to a franchising contract specifying the input price (i) either in terms of the effective marginal cost attained by the upstream firm after having completed the R\&D activity, or (ii) in terms of the initial level of productive efficiency of the OEM unit. This must go along with a compensation scheme rewarding the upstream firm for the risk associated with the project.

Several extensions of the present model are possible as well as desirable, e.g., the analysis of $\mathrm{R} \& \mathrm{D}$ for product innovation or the introduction of upstream or downstream competitors (as in Garvey and Pitchford, 1995). These perspectives are left for future research. 


\section{References}

[1] Antras, P. and E. Helpman (2004), "Global Sourcing", Journal of Political Economy, 112, 552-80.

[2] Futia, C. (1980), "Schumpeterian Competition", Quarterly Journal of Economics, 94, 675-95.

[3] Garvey, G.T. and R. Pitchford (1995), "Input Market Competition and the Make-or-Buy Decision", Journal of Economics and Management Strategy, 4, 491-508.

[4] Grossman, S.J. and O.D. Hart (1986), "The Costs and Benefits of Ownership: A Theory of Vertical and Lateral Integration", Journal of Political Economy, 94, 691-719.

[5] Grossman, G.M. and E. Helpman (2002), "Integration versus Outsourcing in Industry Equilibrium", Quarterly Journal of Economics, 117, 85-120.

[6] Grossman, G.M. and E. Helpman (2005), "Outsourcing in a Global Economy", Review of Economic Studies, 72, 135-59.

[7] Jeuland, A.P. and S.M. Shugan (1983), "Managing Channel Profits", Marketing Science, 2, 239-72.

[8] Katz, M.L. (1989), "Vertical Contractual Relations", in Schmalensee, R. and R.D. Willig, (eds.), Handbook of Industrial Organization, Vol. 1, North-Holland, Amsterdam, 655-721.

[9] Klemperer, P. an M. Meyer (1986), "Price Competition vs Quantity Competition: The Role of Uncertainty", RAND Journal of Economics, 17, 618-38.

[10] Leland, H. (1972), "Theory of the Firm Facing Uncertain Demand", American Economic Review, 62, 278-91. 
[11] McLaren, J. (2000), "Globalization and Vertical Structure", American Economic Review, 90, 1239-54.

[12] Martin, S. (2001), Advanced Industrial Economics. Second Edition, Oxford, Blackwell.

[13] Perry, M.K. (1989), "Vertical Integration: Determinants and Effects", in Schmalensee, R. and R.D. Willig, (eds.), Handbook of Industrial Organization, Vol. 1, North-Holland, Amsterdam, 183-255.

[14] Pritchard, D. and A. MacPherson (2007), "Strategic Destruction of the Western Commercial Aircraft Sector: Implications of Systems Integration and International Risk-Sharing Business Models", The Aeronautical Journal, 111, 327-34.

[15] Sandmo, A. (1971), "On the Theory of the Firm under Price Uncertainty", American Economic Review, 61, 65-73.

[16] Tadelis, S. (2002), "Complexity, Flexibility, and the Make-or-Buy Decision", American Economic Review, 92, 433-37.

[17] Tirole, J. (1988), The Theory of Industrial Organization, Cambridge, MA, MIT Press.

[18] Williamson, O. (1971), "The Vertical Integration of Production: Market Failure Considerations", American Economic Review, 61, 112-23.

[19] Zaccour, G. (2008), "On the Coordination of Dynamic Marketing Channels and Two-Part Tariffs", Automatica, 44, 1233-39. 